\title{
Fly Ash/Paraffin Composite Phase Change Material Used to Treat Thermal and Mechanical Properties of Expansive Soil in Cold Regions
}

\author{
Yong Chen ${ }^{1}$, Yinghao Huang ${ }^{1,2, *}$, Min $\mathrm{Wu}^{1}$ and Shuo Wang ${ }^{1}$ \\ ${ }^{1}$ Geotechnical Engineering Department, Nanjing Hydraulic Research Institute, Nanjing, 210024, China \\ ${ }^{2}$ State Key Laboratory of Hydrology-Water Resources and Hydraulic Engineering Science, Nanjing, 210029, China \\ *Corresponding Author: Yinghao Huang. Email: yhhuang@nhri.cn \\ Received: 21 August 2021 Accepted: 24 September 2021
}

\begin{abstract}
Phase change materials (PCMs) can store large amounts of energy in latent heat and release it during phase changes, which could be used to improve the freeze-thaw performance of soil. The composite phase change material was prepared with paraffin as the PCM and $8 \%$ Class C fly ash (CFA) as the supporting material. Laboratory tests were conducted to reveal the influence of phase change paraffin composite Class C fly ash (CFA-PCM) on the thermal properties, volume changes and mechanical properties of expansive soil. The results show that PCM failed to establish a good improvement effect due to leakage. CFA can effectively adsorb phase change materials, and the two have good compatibility. CFA-PCM reduces the volume change and strength attenuation of the soil, and 8 wt.\% PCM is the optimal content. CFA-PCM turns the phase change latent heat down of the soil and improves its thermal stability. CFA-PCM makes the impact small of freeze-thaw on soil pore structure damage and improves soil volume change and mechanical properties on a macroscopic scale. In addition, CFA-8 wt.\% PCM treated expansive soil has apparent advantages in resisting repeated freeze-thaw cycles, providing a reference for actual engineering design.
\end{abstract}

\section{KEYWORDS}

Composite phase change material; freeze-thaw performance; expansive soil; thermal properties; mechanical properties

\section{Introduction}

Expansive soil, extensively distributed worldwide, is a highly plastic clay rich in hydrophilic solid minerals, such as montmorillonite and illite [1,2]. It has the characteristics of fissure-prone, strong attenuation and strong expansion and contraction. As a result, expansive soil is also called "expanding and shrinking soil". It is prone to expansion and contraction deformation because of changes in external temperatures, which will cause the destruction of the soil structure and the sharp weakening of shear strength. Therefore, it is a typical "cancer soil" in the engineering field [3,4]. Many engineering practices show that expansive soil should not be directly used for cold regions and must be treated [5-7]. At present, to reduce the impact of freeze-thaw (F-T) cycles on the deterioration of expansive soils, chemical agents such as lime [8] and cement $[9,10]$ are usually selected as curing agents. Their reaction with water and soil particles changes the structure and composition of the soil, which can reduce the water 
absorption and expansive properties of the expansive soil, while, the mechanical properties of the soil are improved. For a long time, lime and cement have been used as chemical stabilizers to prevent expansive soil from being damaged by freezing. However, their effectiveness gradually declines over time. For this reason, given the harsh environmental conditions in the cold region, it is urgent to find a new treatment technology that can actively and efficiently improve the freeze-thaw properties of the expansive soil in the cold region.

Phase change materials (PCMs), as an environmental protection and high-performance material, have a significant ability to store energy and improve thermal stability [11-13]. PCMs have been widely used in solar energy utilization [14], building thermal insulation [15], battery thermal management [16] and other fields of energy storage and temperature control [17-19]. Many achievements have been made in improving the low-temperature crack resistance and durability of concrete [20] and asphalt pavement [21]. Manning et al. [22] found that the cooling/heating rate of hot-mixed asphalt fused with PCM is significantly reduced. Lecompte et al. [23] studied the thermal properties of cement mixed with PCM and found that using $30 \%$ (volume ratio) phase change material reduces the depth of heat penetration by $50 \%$. Farnam et al. [24] applied paraffin and methyl laurate as PCM to the concrete pavement structure, showing good ice and snow melting performance. The above PCMs show promising results in controlling the high and low-temperature fluctuations of engineering structures, which provide a theoretical basis to improve the F-T performance of expanded soils in cold regions.

Phase change paraffin is widely used in energy storage applications because of its high phase change latent heat, small volume change, non-toxicity, low cost and controllable phase change temperature. However, leakage problems of paraffin waxes during solid-liquid transition limit their application in construction materials such as asphalt, concrete and walls [25]. When paraffin is mixed too much in the soil, and the solid-liquid phase change occurs, the capillary pores in the soil cannot accommodate the excessive amount of paraffin, which leads to its easy seepage surface the soil. Mahedi et al. [26] incorporated liquid paraffin directly into the loess and found that the high dose of PCM had significant leakage and failed to improve the F-T properties of the soil, which suggests that it is important to find a suitable incorporation method. There is a need to develop shape-stable or shape-stable composites by inserting paraffin into porous materials as a support matrix. Adsorption is an effective method for the preparation of stable phase change composites [27]. Liu et al. [28] used n-dodecane to penetrate carbon to obtain phase change composites with high latent heat and no fading after repeated cycles. Chen et al. [29] created phase change composites by mixing activated carbon with lauric acid, charging capric acid as a phase change medium, and adding halloysite as the support material. Through laboratory experiments, Ji et al. [30] found that the organic PCM dispersed in the thin graphite foam grid has high thermal stability. In their study, the adsorption method was shown effective to inhibit the leakage of phase change paraffin.

In this study, PCM was treated with Class $\mathrm{C}$ fly ash (CFA) as the supporting material (CFA-PCM). CFA is a kind of industrial solid waste, which can improve the strength of the soil. CFA is a porous spherical fine particle with a certain activity, which has specific adsorption properties. This is because the CFA bead wall has a porous structure with porosity as high as $50 \%-80 \%$. Compared with previous adsorption methods, it is a simple operation, cheap, and suitable for engineering construction. The F-T properties of PCM and CFA-PCM were evaluated using filter paper method, volume change, unconfined compressive strength. The scanning electron microscope and differential scanning calorimetry are used to test determine structurally and energetic changes. Further recommendations are provided on PCM content, incorporation method, and chemical stability. 


\section{Materials and Sample Preparation}

\subsection{Materials}

\subsubsection{Expansive Soil}

This study chooses the expansive soil from the water-conveyance canal at the northern Xinjiang Project site (see Fig. 1). The sampling depth of $1 \sim 2 \mathrm{~m}$, the soil is representative whose color is yellowish-brown. According to the Chinese standard for soil test method (GB/T 50123-2019, 2019) [31], the basic physical properties and mineral composition are shown in Table 1. The cumulative curve of particle size gradation is shown in Fig. 2. Among them, the uneven coefficient of the soil is 16, and the curvature coefficient is 1.56, which shows a good gradation. An X-ray diffractometer was used to measure the mineral components. It can be found that montmorillonite is the main mineral component of expansive soil, indicating that expansive soil has a high degree of expansion and contraction.

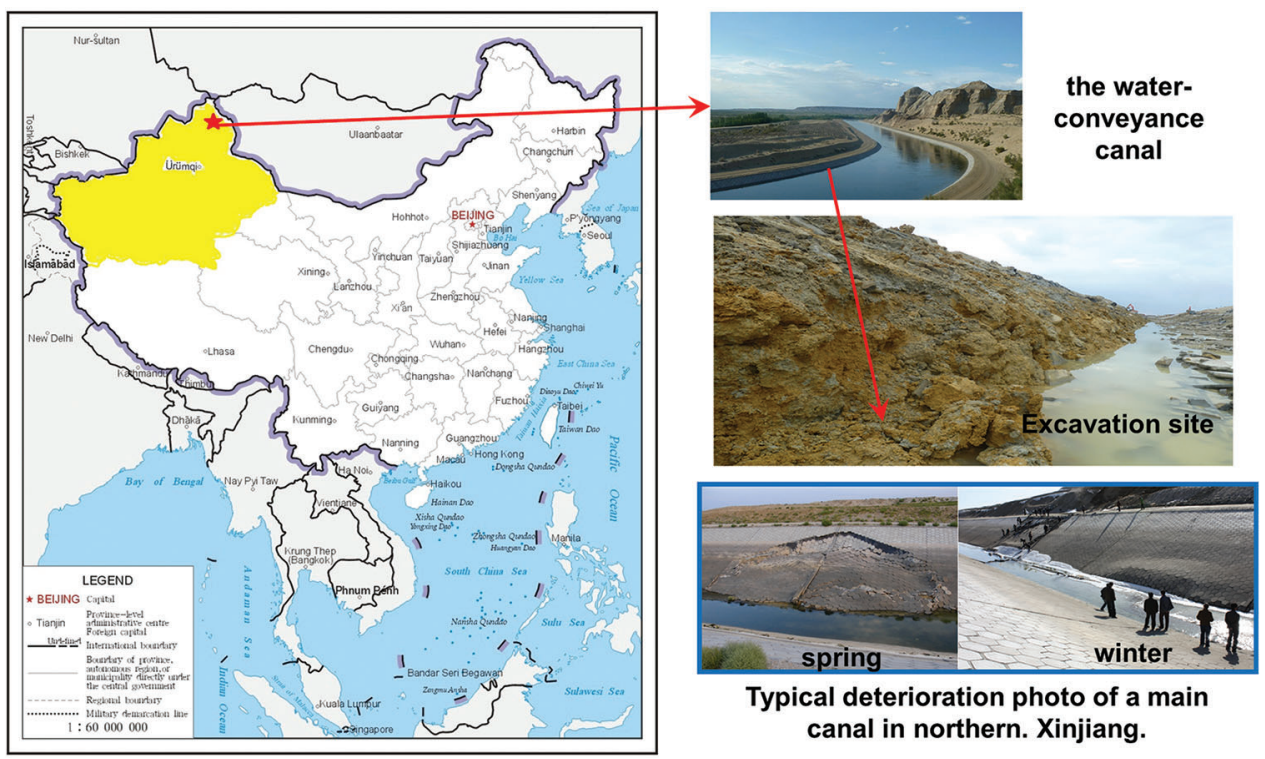

Figure 1: Photo of the canal location and scene

Table 1: Explosive soil physical properties and mineral compositions

\begin{tabular}{lll}
\hline Property & Index & Value \\
\hline Physical properties & Specific gravity $(\mathrm{Gs})$ & 2.67 \\
& Potential expansion $\left(\delta_{\mathrm{ef}}\right)$ & 71 \\
& Compaction study & \\
& Optimum moisture content $\left(w_{\mathrm{op}}, \%\right)$ & 18.4 \\
& Maximum dry density $\left(\rho_{\mathrm{dmax}}, \mathrm{g} / \mathrm{cm}^{3}\right)$ & 1.71 \\
& Consistency limit & \\
& Liquid limit $\left(\mathrm{W}_{\mathrm{L}}, \%\right)$ & 51.9 \\
& Plastic limit $\left(\mathrm{W}_{\mathrm{P}}, \%\right)$ & 18.6 \\
& Plasticity index $\left(\mathrm{I}_{\mathrm{P}}, \%\right)$ & 34.2 \\
\hline & & (Continued $)$
\end{tabular}




\begin{tabular}{lll}
\hline Table 1 (continued). & & \\
\hline Property & Index & Value \\
\hline Mineral compositions & Montmorillonite (\%) & 61.4 \\
& Quartz (\%) & 30.9 \\
& Feldspar (\%) & 7.1 \\
& Albite and Calcite (\%) & 0.6 \\
\hline
\end{tabular}

\subsubsection{Fly Ash}

The fly ash comes from Henan Power Plant and is Class C fly ash (CFA). With $16.2 \%$ fineness (5 $\mu$ m sieve residue), $4.71 \%$ ignition loss, $1.12 \mathrm{~g} / \mathrm{cm}^{3}$ bulk density and $0.85 \%$ moisture content. As shown in Table 2, the additive has the following main chemical compositions. The cumulative curve of particle size gradation is shown in Fig. 2.

Table 2: Chemical compositions of CFA

\begin{tabular}{llllllll}
\hline Oxide/constituent & $\mathrm{SiO}_{2}$ & $\mathrm{Al}_{2} \mathrm{O}_{3}$ & $\mathrm{Fe}_{2} \mathrm{O}_{3}$ & $\mathrm{CaO}$ & $\mathrm{MgO}$ & $\mathrm{SO}_{3}$ & $\mathrm{TiO}_{2}$ \\
\hline Mass (\%) & 49.12 & 24.23 & 8.79 & 8.65 & 5.94 & 2.18 & 1.09 \\
\hline
\end{tabular}

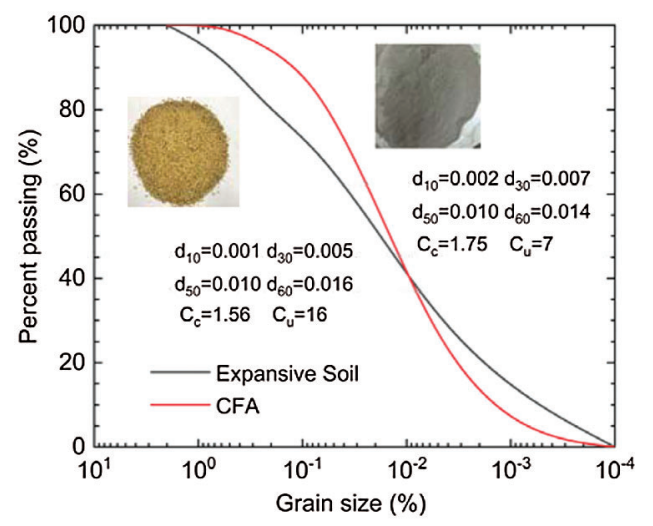

Figure 2: Gradation curve of expansive soil and class C fly ash

\subsubsection{Phase Change Material}

A commercially available paraffin-based PCM from a manufacturer certified by a CCS (Chinese Chemical Society) was chosen (see Fig. 3). It has low price, large latent heat and appropriate thermal characteristics such as little or no supercooling, low vapor pressure, etc. Because the average annual temperature along the canal is $3.4^{\circ} \mathrm{C}$, the selected PCM has a phase change temperature of $4.5-5.5^{\circ} \mathrm{C}$. The PCM is colorless and odorless in appearance, and the PCM is liquid at room temperature. Its phase change enthalpy is $258.0 \mathrm{~J} / \mathrm{g}$, and its specific gravity is $0.76 \mathrm{~kg} / \mathrm{L}$. During phase changes, there is also little expansion or contraction, and its performance is stable at high and low temperatures. 


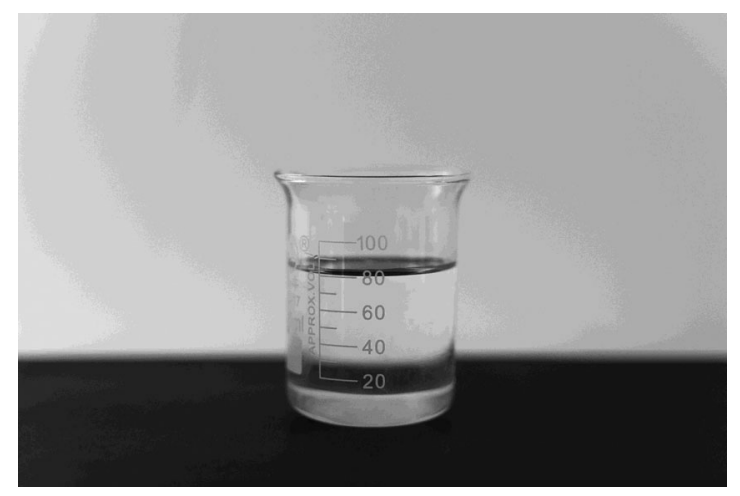

Figure 3: Phase change material

\subsection{Sample Preparation}

The unprocessed expansive soil was tumbled, naturally dried and crushed, and then passed through a $2 \mathrm{~mm}$ sieve. A moisture content of $5.18 \%$ is found in the sieved soil. First, $8 \%$ (by weight of dry soil) of CFA was added to the air-dry soil, and after mixing well, PCM was added to the air-dry soil and mixed well according to the mixing ratios $(5 \%, 8 \%$ and $10 \%$ by weight of dry soil) of the test target. After that, evenly spray distilled water into the soil, mix well and put it into a sealed bag to smother the material for one day and night so that the moisture is evenly distributed. Use the standard sample preparation machine and automatic release mechanism to make samples. The compaction of all samples was controlled to be $95 \%, 18.4 \%$ moisture content, $80 \mathrm{~mm}$ height, and $39.1 \mathrm{~mm}$ diameter. The prepared samples were wrapped with cling film and grouped and numbered as shown in Table 3. For example, "IC-P8" means CFA stabilizes the sample, 8\% PCM content, and so on. Before the F-T cycle test, all samples were placed in sealed bags to cure for 7 days.

Table 3: Experimental setup of the study

\begin{tabular}{lllll}
\hline Treatment type & Mix ID & $0 \%$ CFA & Mix ID & $8 \%$ CFA \\
\hline Expansive soil-CFA & I-0 & 0 & & \\
PCM (\%) & I-P5 & 5 & IC-P5 & 5 \\
& I-P8 & 8 & IC-P8 & 8 \\
& I-P10 & 10 & IC-P10 & 10 \\
\hline
\end{tabular}

\section{Methods}

\subsection{Freeze-Thaw (F-T) Cycle Tests}

Testing for F-T cycles is sensitive to different freezing temperatures and times [32], and a majority of the current F-T cycle tests use these methods: freeze for $12 \mathrm{~h}$ at $-20^{\circ} \mathrm{C}$; thaw for $12 \mathrm{~h}$ at $20^{\circ} \mathrm{C}$, which is too general and not targeted. Fig. 4 shows the surface temperature distribution observed by a weather station along the main canal section of the northern Xinjiang canal from 2013 to 2014. The annual average temperature is below $0^{\circ} \mathrm{C}$ for about 4 months $(2013 / 11 / 20 \sim 2014 / 3 / 19)$; this process can be regarded as the soil has experienced a freeze. The average temperature is above $0^{\circ} \mathrm{C}$ for about 8 months $(2014 / 3 /$ 19 2014/11/11); this process can be regarded as the soil has experienced thaw. From the above canal temperature changes, it is finally determined that the laboratory simulated on-site freeze state temperature is $-21.5^{\circ} \mathrm{C}$, and the duration is $12 \mathrm{~h}$; the simulated on-site thaw state temperature is $22.5^{\circ} \mathrm{C}$, and the time 
is $24 \mathrm{~h}$. According to the experimental conclusions of predecessors [33,34], seven F-T cycles will be performed on the sample. All processes are set in the programmable low and high-temperature test machine of the Institute of Cold and Drought Environment and Engineering, Chinese Academy of Sciences.

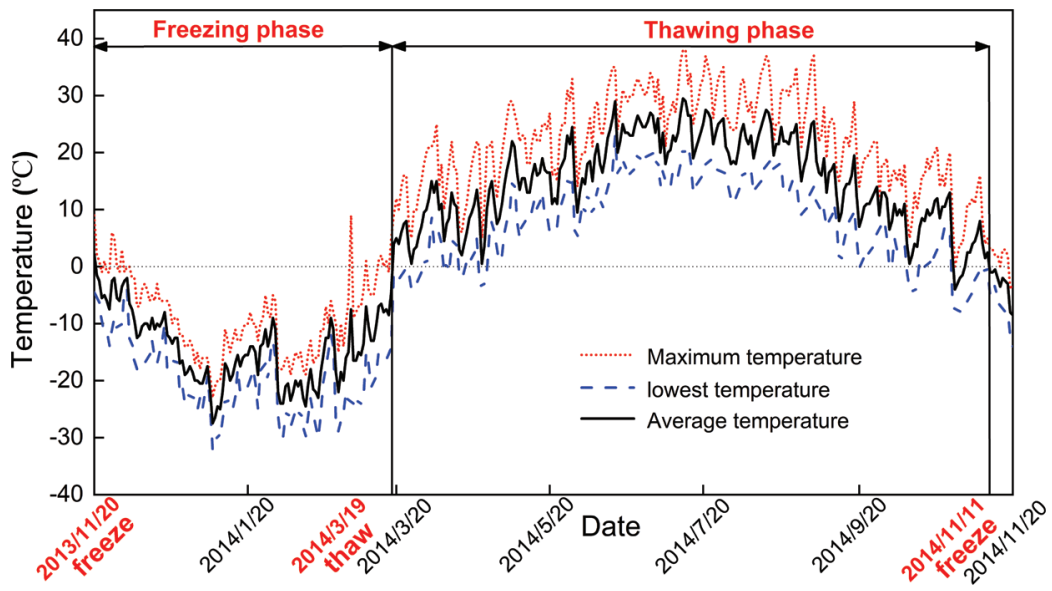

Figure 4: Average temperature of the canal (2013 to 2014)

\subsection{Filter Paper Method}

Many studies have found that high-volume paraffin-based liquid PCMs will seep out of building materials such as cement and soil [25,26]. In this study, CFA was selected as a stabilizer. CFA had good adsorption properties and can inhibit the exudation of paraffin oil to a certain extent. We cut a $2 \mathrm{~cm}^{3}$ cube from the center of the sample and placed it on a $\mathrm{d} 11 \mathrm{~cm}$ medium-speed filter paper to observe the seepage of paraffin oil on the filter paper. The lighter the color and the smaller the area, the less paraffin exudation and the better the resistance of the CFA to paraffin exudation.

\subsection{Differential Scanning Calorimetry (DSC) Tests}

Differential scanning calorimetry (DSC) was used to test the phase transformation temperature and latent heat $\cdot$ of the samples. The test instrument is the QL-2000 Differential Scanning Calorimeter of the Institute of Cold and Drought Environment and Engineering, Chinese Academy of Sciences. The cooling and heating rate was set to $5{ }^{\circ} \mathrm{C} / \mathrm{min}$. Using a high-precision balance with a $10-4 \mathrm{~g}$ accuracy, the sample was weighed with a weight of $10 \pm 2 \mathrm{mg}$. A test was performed by lowering the temperature slowly to $-20^{\circ} \mathrm{C}$ for $2 \mathrm{~min}$, and then increasing it to $20^{\circ} \mathrm{C}$. A sample was kept at $20^{\circ} \mathrm{C}$ for $2 \mathrm{~min}$ before being cooled down to $-20^{\circ} \mathrm{C}$. The DSC curves were taken from the 2 nd temperature cycle to eliminate the pre-temperature course of the sample on the DSC test results.

\subsection{Volume Change Tests}

Five parallel samples were set up in each group for the volume change tests. Every time the sample is frozen and thawed, measure its volume with a digital vernier caliper. Height and diameter were measured three times each in the vertical direction on each end of the cross-section. Then take the average of each to calculate the volume of the sample. An electronic balance monitors a sample quality change after each sample size measurement is complete to avoid water loss.

\subsection{Unconfined Compressive Strength (UCS) Tests}

An unconfined compression tester was used to perform these UCS tests, as shown in Fig. 5. The test was carried out at the Nanjing Institute of Water Conservancy Science. Testing was done on samples after 0 
(initial state), 1, 3, and 7 F-T cycles. Computers automatically collect the test data in three parallel tests conducted. The shear test set the strain rate was $1 \% /$ min and stopped when the axial strain reached $20 \%$.

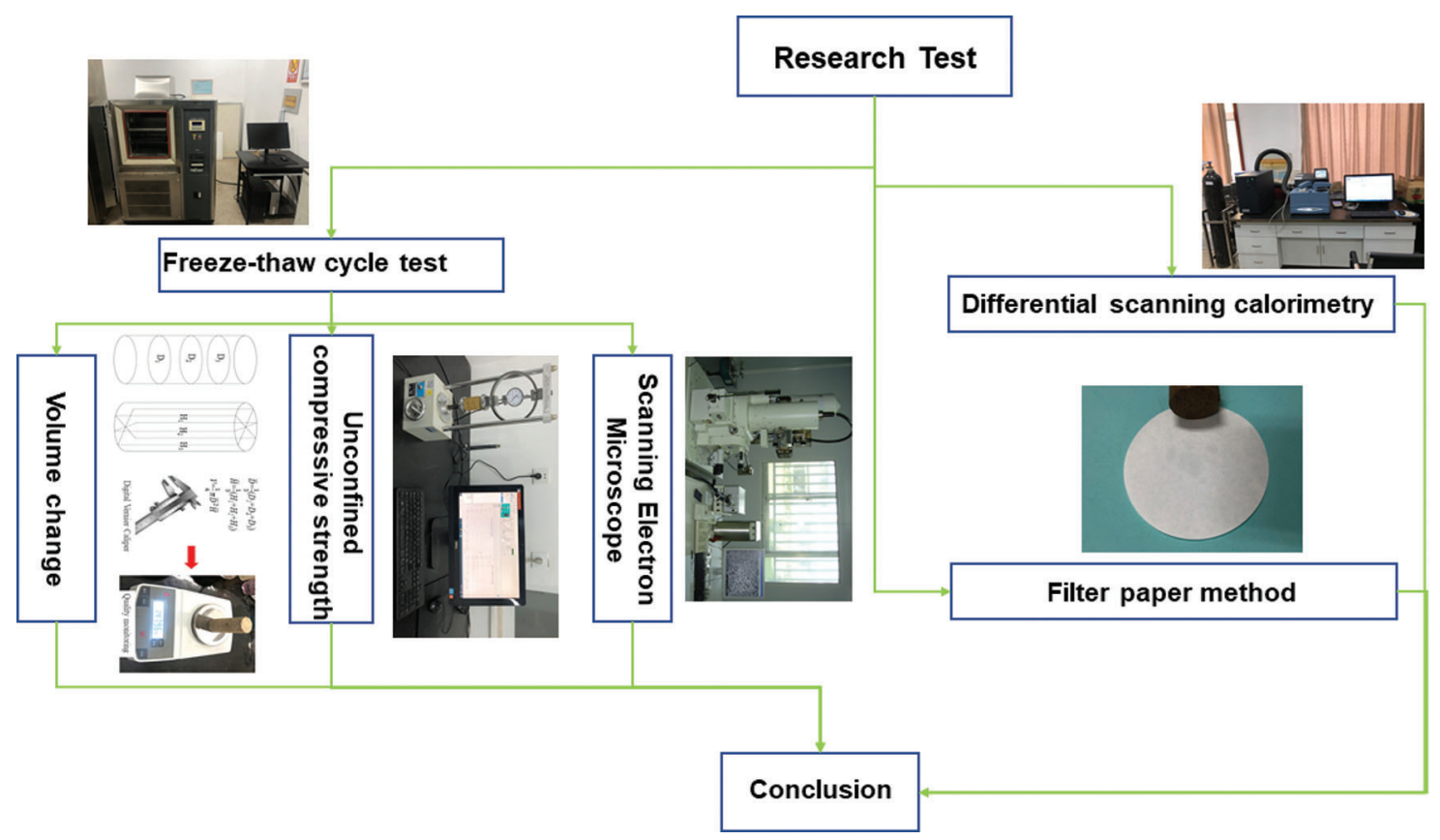

Figure 5: Flow chart of the study

\subsection{Scanning Electron Microscope (SEM) Tests}

The microscopic test was carried out using the SU8020 cold field emission SEM of the Lanzhou Institute of Chemical Physics, Chinese Academy of Sciences. For the samples undergoing different F-T cycles, a soil sample with a volume of $5 \mathrm{~mm} \times 5 \mathrm{~mm} \times 5 \mathrm{~mm}$ was cut from a specific site at the center. Then spray the metal coating and put it into the SEM sample region together with the base. By adjusting the position of the sample, focus near the observation region, and select representative points to take pictures.

\section{Results and Discussion}

\subsection{Exudation of Paraffin}

Paraffin is a solid-liquid PCM [35]. When the amount of paraffin in the soil is too high, the capillary pores cannot hold the excess paraffin, making it easy to seep from the surface. This experiment tested the paraffin exudation of samples under different paraffin content, as shown in Figs. 6a-6c. When the paraffin content was $5 \%$, there were no prominent oil spots on the filter paper under the sample, which means there was no paraffin exudation. When the paraffin content is $8 \%$, there were obvious oil spots formed by paraffin exudation on the filter paper, which means there was paraffin exudation. It can be judged that the maximum content of paraffin without leakage is between $5 \%$ and $8 \%$. Similarly, the antiparaffin exudation properties of CFA-PCM under different paraffin content were tested, and the results are shown in Figs. 6d-6f. It can be found that the maximum content of paraffin in CFA-PCM that does not leak is between $8 \%$ and $10 \%$. The capacity of the sample to store paraffin increased by $3 \%$.

Expansive soil is a kind of cohesive soil, which contains more hydrophilic clay minerals such as montmorillonite, and has specific adsorption properties [36]. The clay minerals (such as montmorillonite) adsorb part of the PCM when in contact with it. At the same time, the capillary pores between the soil particles can contain a small amount of paraffin, so the low content of PCM will not leak. CFA is a 
porous spherical fine particle with a particular activity, has a specific adsorption performance and a strong gelling effect, and can form a three-dimensional network structure with soil particles. The PCM is surrounded by the mesh and cannot flow freely in the mesh structure, thus creating a semi-solid, which is not easy to leak. When the solid-liquid phase transition occurs, the paraffin in the matrix can be stored in the network structure without exudation. Therefore, the anti-paraffin exudation property of CFA-PCM is improved, and the maximum amount of paraffin is increased.

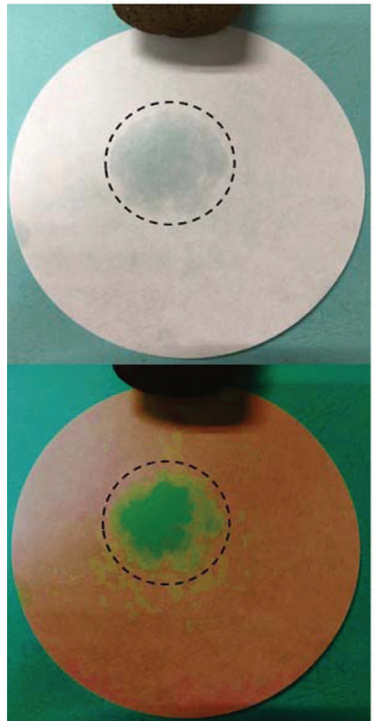

(a)

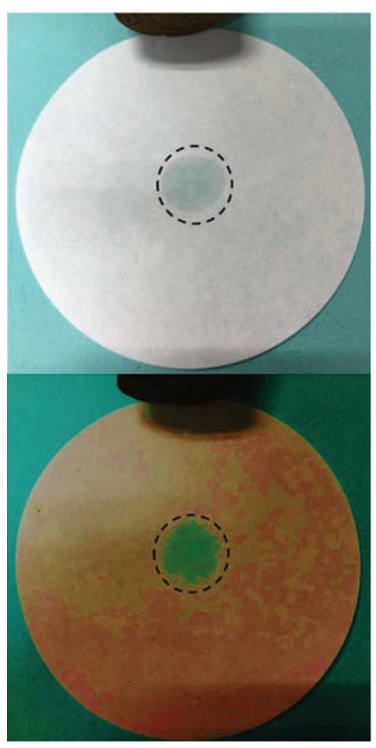

(d)

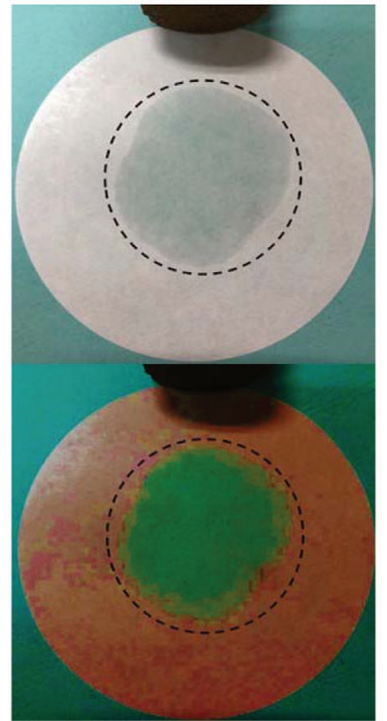

(b)

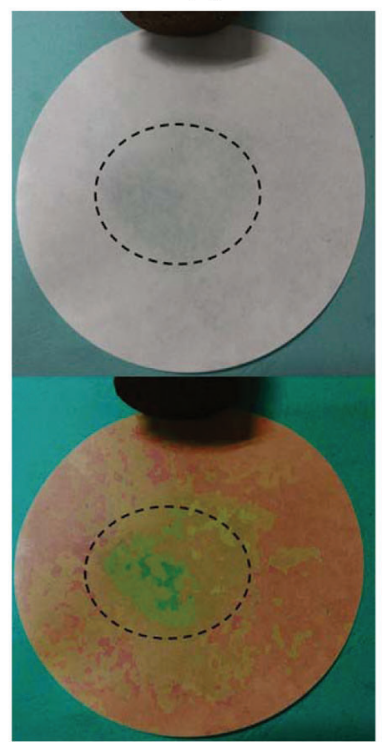

(e)

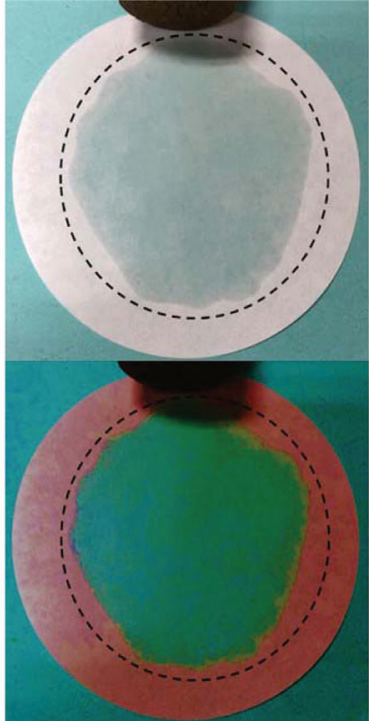

(c)

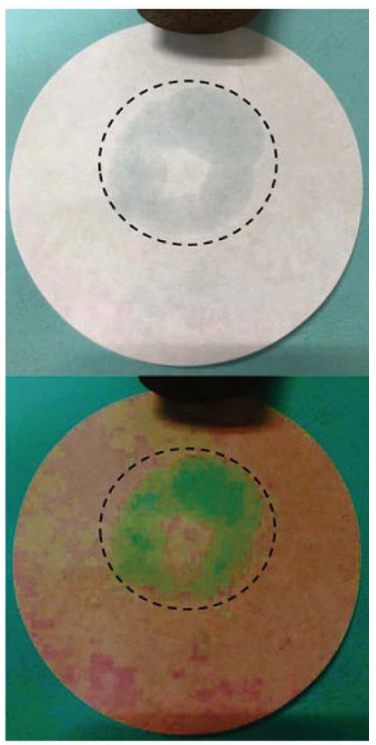

(f)

Figure 6: Exudation of PCM in the samples (inside the dashed line is the exuded PCM) (a) I-P5 (b) I-P8 (c) I-P10 (d) IC-P5 (e) IC-P8 (f) IC-P10 


\subsection{Thermal Property}

The main component of paraffin-based PCM is saturated alkanes, which have a stable chemical structure [37], and generally do not chemically react with expansive soil and CFA. The DSC of paraffin, I-0 and ICP10 was tested in this test, and the curve is shown in Fig. 7. From Fig. 7, the phase change latent heat of the expanded soil is decreased by about $10.93 \%$ when PCM (10\% content) is used. In this case, the reaction of PCM at 5.21 2.76 ${ }^{\circ} \mathrm{C}$ released heat into the soil, which made part of the water not freeze. With PCM adding to the soil, the "original peak" phase change temperature increased from $-7.61{ }^{\circ} \mathrm{C}$ to $-5.97^{\circ} \mathrm{C}$, indicating that both freeze and thaw warmed the soil. Similarly, the widths of peaks at the phase transitions also increased, respectively, and a moderate slowdown of the subcooling phenomenon. It shows that the PCM and mechanical blending delayed the ice lens formation at the test temperatures. Therefore, the internal temperature field of the soil is improved, which enhances the thermal stability of the soil.

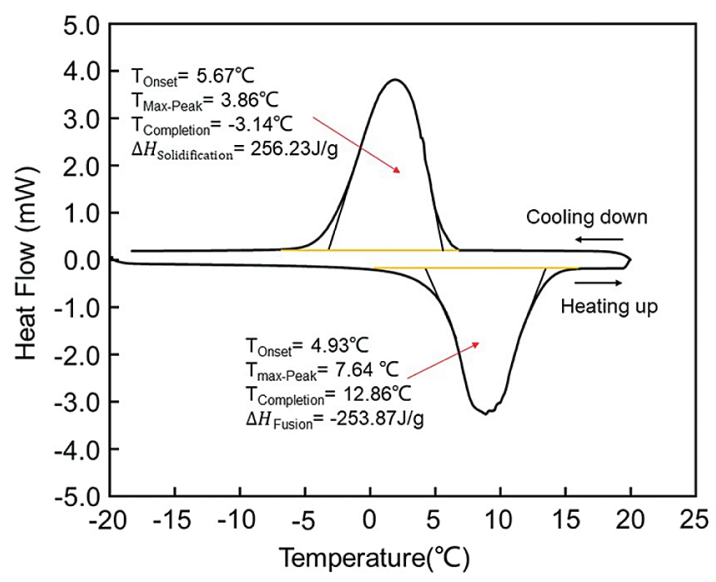

(a)

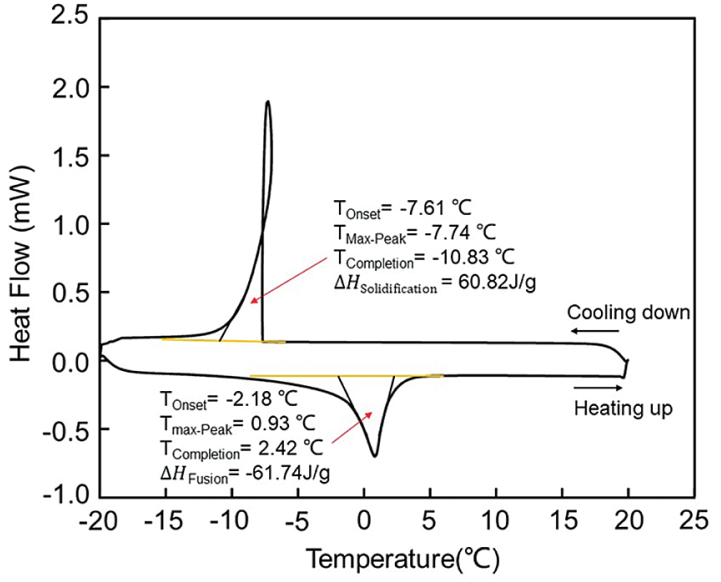

(b)

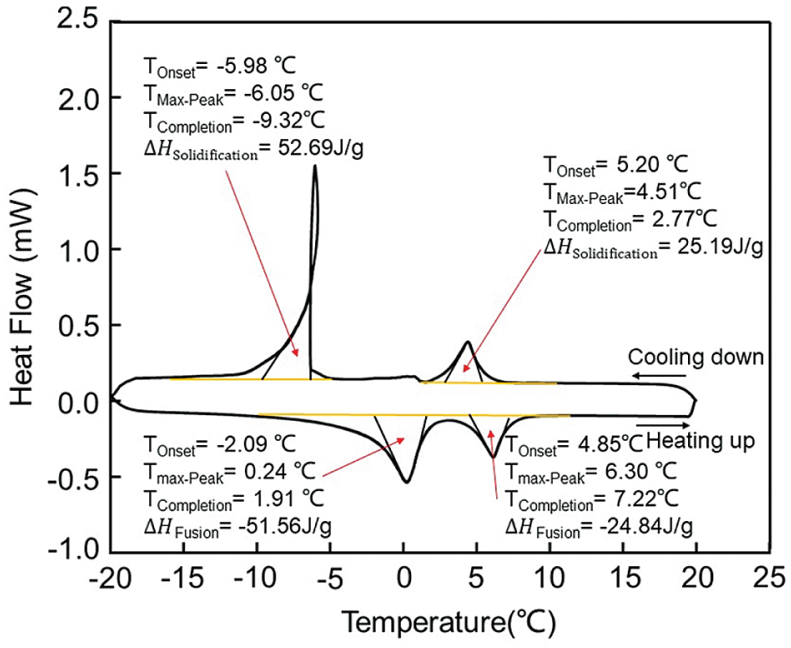

(c)

Figure 7: DSC curves (a) paraffin (b) I-0 (c) IC-P10

The DSC results indicate that the measured phase change enthalpy of CFA-PCM may not reach its theoretical value (see Figs. 7a and 7c). The difference between the measured and theoretical phase change enthalpies may be due to the inhibition of the PCM phase change process by the pore structure of the 
expansive soil, as shown in Fig. 8. Expansive soil is a typical porous medium composite material. There is a weak interaction between its pore structure and PCM [38], such as capillary force, surface polarity, hydrogen bond and van der Waals force. These weak interactions inhibit the movement of long-chain paraffin-based PCM molecules. For the PCM in the microporous structure and located near open-pore boundaries (see the blues legend in Fig. 8), the grain structure that can be formed under the constraint of weak intermolecular interactions is generally disordered. This will create disturbances to the crystallization process of PCM, which will lead to the low measured latent heat of solidification of PCM due to incomplete crystallization in severe cases [39]. However, the PCM in the free zone (see the red legend in Fig. 8) is less affected by the weak interaction between the molecules because it is far from the edge of the open pore. Therefore, this part of the PCM is easier to form an ordered grain structure. The latent heat of solidification phase change that can be released is not apparent compared with the theoretical latent heat.

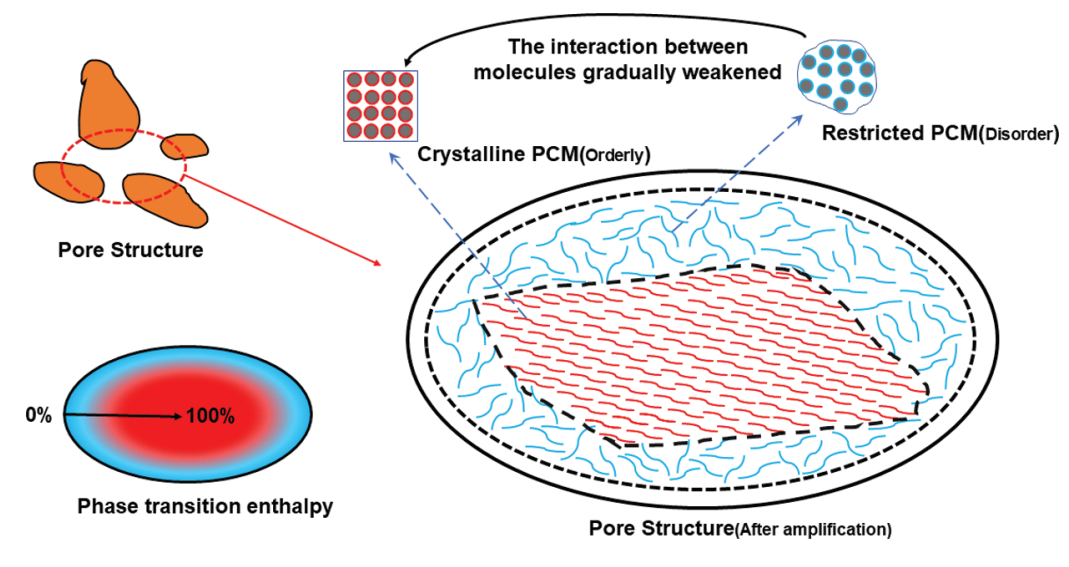

Figure 8: Inhibition of crystallization of PCM by the pore structure

\subsection{Volume Changes}

Fig. 9 shows the changes in sample volumes caused by different content after F-T cycles. " $F$ " in the abscissa indicates the completion of freezing, while " $\mathrm{T}$ " indicates the completion of thawing completion. In the F-T cycle, there was a "freeze-contraction and thaw-expansion" of the sample. As shown in Fig. 9, we observed a reduction in the volume of the I-P5 sample by about 7\%. When the addition amount was increased, I-P8 and I-P10 samples reduced the volume change by approximately $21 \%$ and $28 \%$, respectively. However, there was only a tiny improvement in volume change after multiple F-T cycles due to PCM leakage when the F-T cycles increased. This phenomenon was similar to observed in the study carried out by Mahedi et al. [26], who investigated PCM and improved the F-T performance of loess. The volume change of IC-P samples was moderately affected by the F-T cycle and showed a clear "freeze-contraction and thaw-expansion". The volume change rate is positive when freezing, whereas it is negative when thawing. The absolute value of the volume change rate of the IC-P5 sample was kept at about $2 \%$. The total value of the volume change rate of the IC-P8 sample was observed to be reduced by about $1 \%$. The greater PCM content in the IC-P sample, the more minor volume change is achieved, whereas the lower the maximum freeze swelling rate, the maximum thawing shrinkage rate. As the PCM content was increased to $10 \%$, a decrease in volume change rate was no longer apparent. The comprehensive economic and construction process considerations indicate the existence of optimal content. 


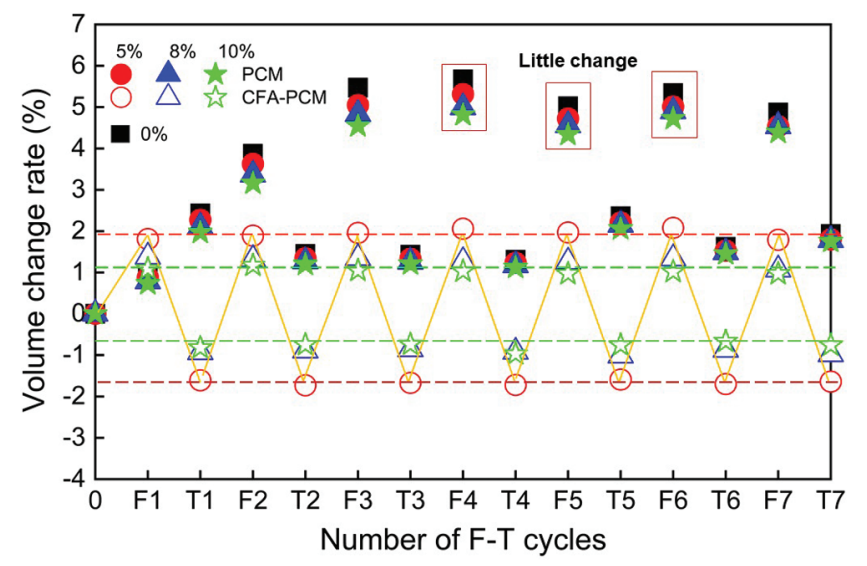

Figure 9: Volume changes of samples during F-T cycles

Under negative temperature conditions, the water phase turns into ice, and the volume increases by about $9 \%$. The expansion soil particles shrink during this process due to the water loss from freezing, whereas thawing was precisely the reverse process. The increase in water volume during freezing was greater than the shrinkage of soil particles, while we observed the opposite is the phenomenon during thawing. This is because the initial water content of the sample is significant. The volume expansion of the liquid water phase into solid ice when it freezes is more significant than the shrinkage of the expanded clay particles when they lose water, and the opposite is true when they melt. Therefore, the macroscopic performance is "frost heaving and thaw collapsing". During the whole F-T cycle test, pure PCM failed to exhibit optimum performance in reducing the volume change. This is because PCM belongs to organic hydrocarbons, and it is insoluble in water and does not immerse into the soil. During the thawing process, PCM in the sample changed from a solid phase to a liquid phase. Affected by the difference in gravity, some portion of the PCM migrated from the upper part of the sample to the lower part, precipitating out from the neighboring area, causing leakage. For the CFA-PCM sample, the hydration of fly ash produced a hardened hydrated calcium silicate gel, which inhibited the deformation of the soil [40]. In addition, due to the porous adsorption performance of CFA, the overall leakage of PCM after phase change and melting was reduced by more than $84 \%$, which improved the stability of PCM. Therefore, during the phase change process, CFA-PCM stores or releases heat as latent heat. It can reduce the volume change and make the soil more stable by controlling the temperature field inside the expansive soil sample.

\subsection{Mechanical Properties}

\subsubsection{Stress-Strain Behavior}

Fig. 10 shows the stress-strain curve of the samples (limited to space, only the stress-strain curve of $0 \%$, $8 \%$ PCM content is listed), where FT indicates the number of freeze-thaw cycles. The stress-strain curves of this test all showed a strain-softening type. According to Fig. 10a, the F-T cycle significantly affected the stress-strain curve for the expansive soil sample, with the 1st cycle having the most significant effect. In the initial state, the plastic deformation duration of the expansive soil samples is longer. After the F-T cycles, the plastic deformation duration was significantly reduced. As the number of F-T cycles increases to three, expansive soil's mechanical properties gradually stabilize. From Fig. 10b, it can be found that the stress-strain curve of PCM modified expansive soil samples had increased plasticity over time, which indicated that PCM could improve the toughness of the soil to a certain extent. The main reason is that PCM is not immersed in the soil, and the pores between soil particles are changed from air to PCM. The performance of PCM is similar to that of cementitious material, and it can be hardened in air and water, 
thus delaying the stress softening of the soil [37]. The CFA and the expansive soil have undergone ion exchange and aggregation, which reduced the thickness of the water film adsorbed by the soil particles and reduced the plasticity of the soil (see Fig. 10c).

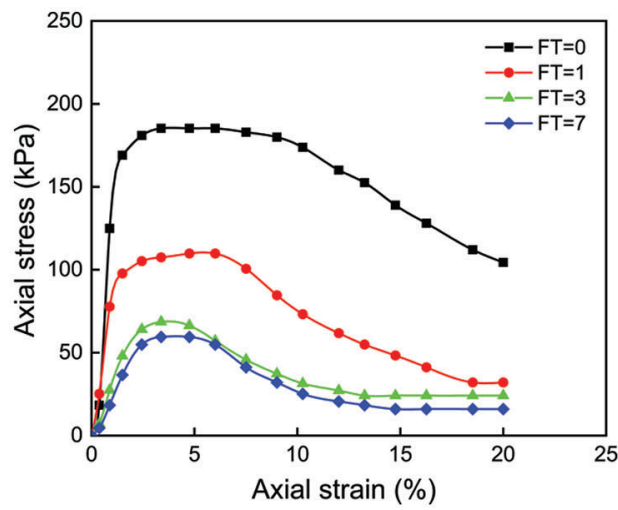

(a)

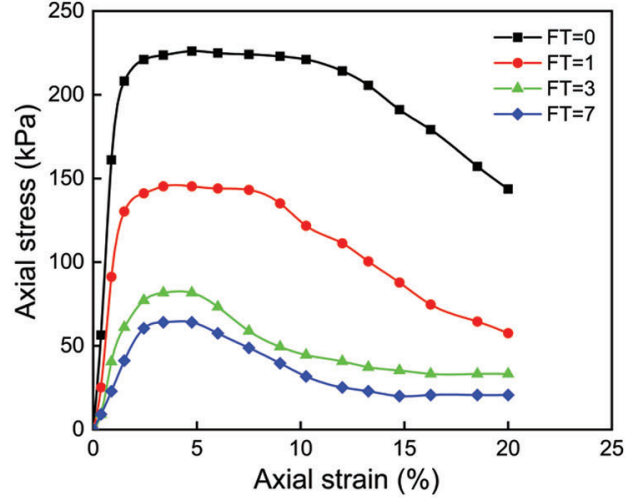

(b)

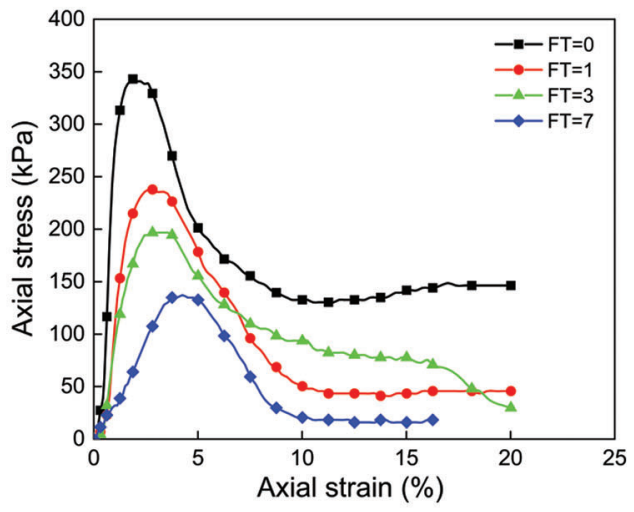

(c)

Figure 10: Stress-strain relationship curve for samples under different F-T cycle (a) I-0 (b) I-P8 (c) IC-P8

\subsubsection{Strain at Failure}

The strain at failure is an important parameter to measure soil deformation. On the "softening type" stress-strain curve, the strain at failure is the axial strain corresponding to the peak point of the axial stress [41]. Fig. 12 shows the variation of the strain at failure of samples with the number of F-T cycles. The first F-T cycle has the most significant impact on the strain at failure three times tends to be steady. The PCM and the pure soil sample showed similar laws, and the strain at failure with the F-T cycles showed a good exponential relationship (negative correlation). However, the PCM strain at failure is more significant under the same F-T cycles than in the pure soil sample. This shows that PCM has a certain positive significance for the strain at failure of expansive soil. For the PCM modified expansive soil, the strain at failure has a good linear relationship (positive correlation) with the number of F-T cycles. This is different from the first two and is an interesting phenomenon. The above phenomenon can be explained as the incorporation of CFA in the initial state aggravates the brittleness of the soil. As the number of F-T cycles increases, the soil expansion and contraction, the degree of compaction becomes lower, and the strain at failure increases. 


\subsubsection{UCS}

A soil with general strain-softening, the unconfined compressive strength (UCS) is usually expressed by the peak value of the stress-strain curve [42]. The UCS of the samples in the initial state $(\mathrm{FT}=0)$ varied considerably with different PCM content levels (see Fig. 11). Initial, while PCM content was increasing, soil UCS increased and then decreased. When the PCM content is low, the soil particles become cemented, resulting in a highly strong mixture. As the content increased to $10 \%$, the PCM may have a relatively concentrated distribution, gradually creating a soft liquid surface inside the sample, thereby reducing the strength of the soil. The CFA-PCM sample shows a similar change curve. Still, CFA can effectively improve the agglomeration and compatibility of the soil, reduce the "moisture content", so the strength of the soil is significantly increased. The soil strength of $5 \%$ content does not change significantly for PCM, and 10\% increases the strength significantly. Therefore, $8 \%$ content shows better superiority in improving the strength of expansive soil.

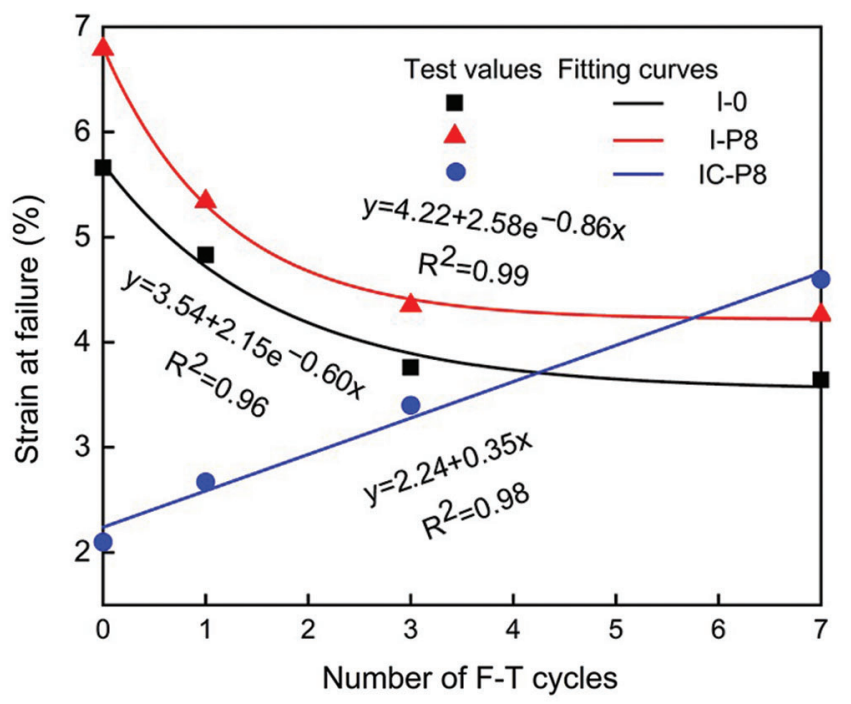

Figure 11: Curves of strain at failure vs. number of F-T cycles

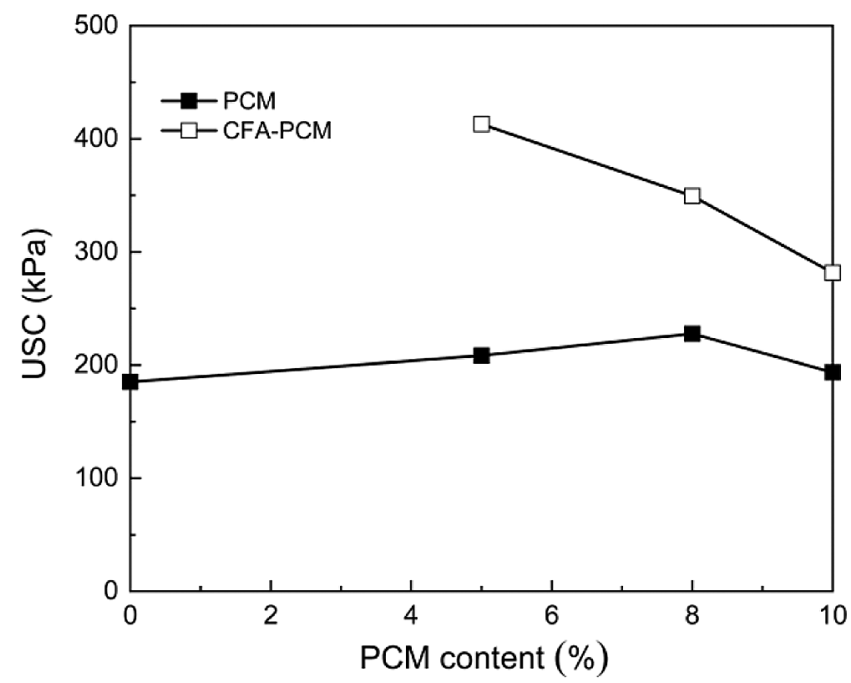

Figure 12: Effect of different PCM admixture on soil strength in the initial state 
To intuitive compare F-T cycle effects on degradation of UCS, the UCS was normalized at each PCM and CFA-PCM content (see Fig. 8). As follows, the normalized UCS $\left(\bar{q}_{u}\right)$ is defined as [43]:

$\bar{q}_{u}^{i}=q_{u}^{i} / q_{u}^{0}, i=1,3,7$

where $\mathrm{i}$ is the number of F-T cycles, $q_{u}^{i}$ the UCS after i F-T cycle and $q_{u}^{0}$ the UCS after in the initial state ( 0 cycles). Fig. 13 shows the influence curve of F-T cycles on the strength of different PCM samples. In the first F-T cycle, the strength of soil was significantly attenuated. This result is caused by the complex ice-water change and the volume change of the expansive soil, which significantly alters the pore distribution and damages the soil structure. After three cycles, the strength decay of the samples slowed down and stabilized. There is a big difference between PCM and CFA-PCM in improving soil strength attenuation. The specific manifestations were as follows: As shown in Fig. 13a, the strength attenuation coefficients of the 5\% and 10\% PCM samples were lower than those of the pure soil samples, and only a slight improvement in the strength attenuation of the soil was observed at $8 \%$ content. While CFA-PCM had a positive effect on soil strength attenuation, the greater the PCM admixture, the more obvious it was, but there was optimal content. As the number of F-T cycles increased (see Figs. 13b and 13c), the inability of PCM to improve soil strength decay became more pronounced. For CFA-PCM samples, CFA undergoes ion exchange and flocculation with swelling soil particles to produce a high-strength gelling substance. In addition, the hydration of CFA and other effects reduced the leakage of PCM, and PCM performs its role stably. Therefore, the UCS of the CFA-PCM samples in the initial state was significantly higher than that of the PCM samples. The $\bar{q}_{u}$ of the CFA-PCM samples was significantly higher after 7 F-T cycles.

\subsection{Microscopic Analysis}

\subsubsection{SEM}

The CFA-PCM samples were selected for microscopic tests because they exhibited a more stable performance. Fig. 14 shows an image scanned at 100x magnification by an electron microscope. Initial, the soil particles were glued together to form a whole, and the soil sample showed good integrity. The pores of the sample began to develop after one F-T cycle. After seven cycles, obvious cracks were formed inside the soil, which eventually resulted in damage to the soil structure, resulting in deterioration of macro-mechanical properties. CFA has the function of filling the soil's pores so that the large pores of the soil are filled, resulting in a significant decrease in the porosity of the improved expansive soil. At the same time, CFA can effectively improve the cementing performance of the bulk structure, reduce the connectivity of the pores, and form an obstacle to the flow of water, thereby expanding soil expand and contract are no longer obvious.

Based on the digital image processing technology Image-J performs a series of pre-processing on the collected images (such as grayscale correction, denoising, brightness and contrast adjustment, etc.), and then sets appropriate thresholds [44] to convert the collected images into binary images. Through calculation and analysis of binary images, quantitative information such as surface porosity and pore orientation are obtained. Fig. 15 shows the surface porosity (the proportion of pores on a certain plane) of the sample after undergoing different numbers of F-T cycles. The sample surface porosity gradually increased after each F-T cycle, and the increase rate gradually slowed down after three cycles. After seven cycles, the surface porosity of the samples with the 4 PCM contents $(0 \%, 5 \%, 8 \%$ and $10 \%)$ increased by $15.4 \%, 11.89 \%$, $8.65 \%$ and $7.27 \%$, respectively. Macroscopically, CFA-PCM reduces the effect of F-T cycles on the soil mechanical properties. The change rule of surface porosity is roughly negatively correlated with the change of sample strength. Also, it was discovered that the higher the PCM content was in the early stage of testing, the slower the soil porosity increased. This is because when PCM content is low, it cannot produce enough heat to prevent the waters from changing into ice crystals, causing damage to the soil particles around it. As a result, soil microstructure changes more radically after the F-T cycle test. 


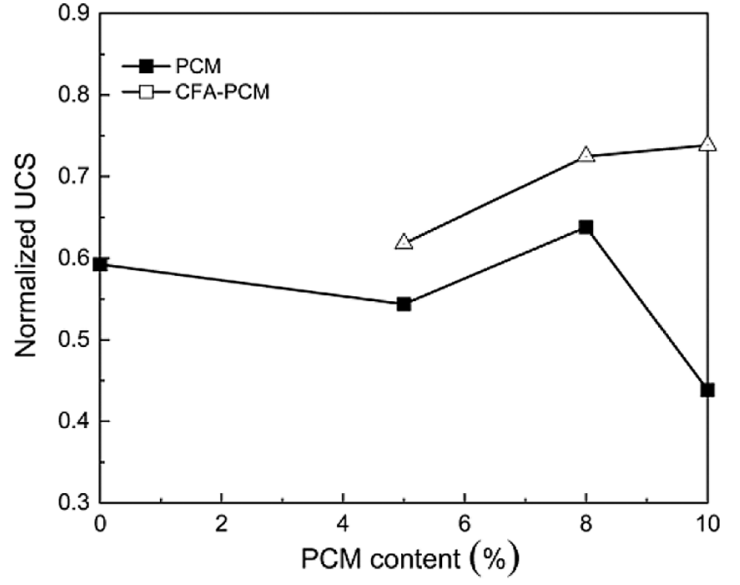

(a)

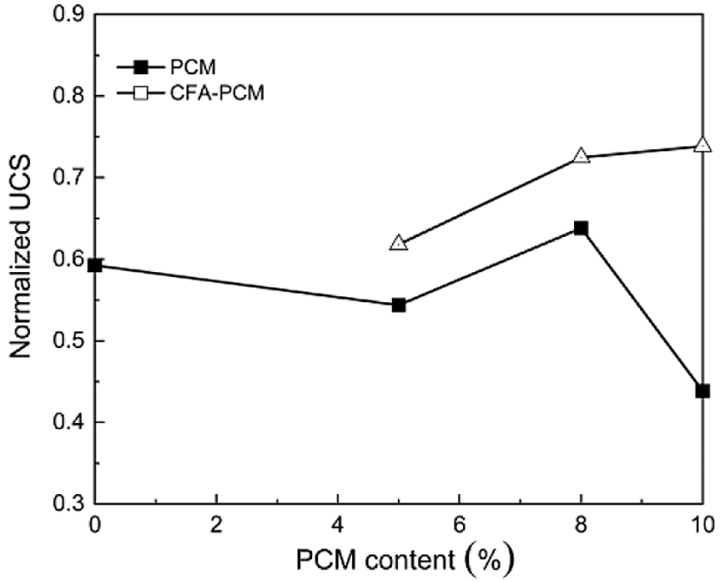

(b)

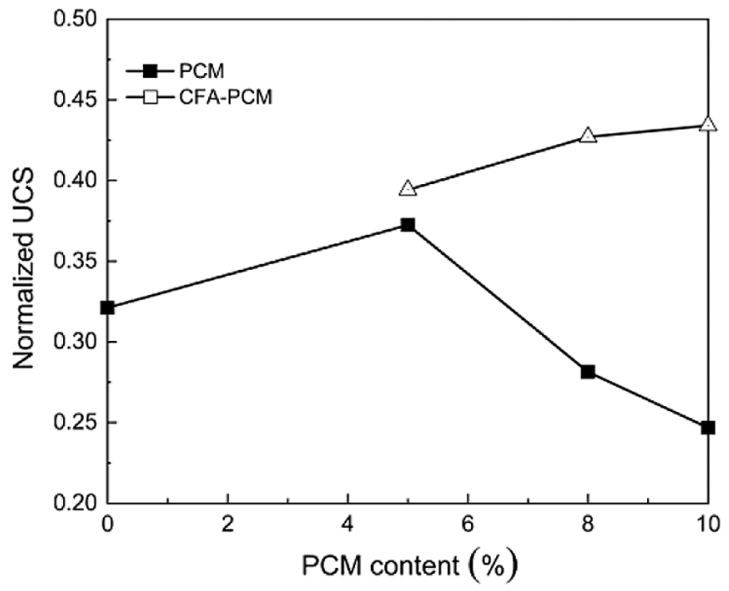

(c)

Figure 13: Changes of UCS with the number of F-T cycles (a) 1 cycle (b) 3 cycles (c) 7 cycles

Probabilistic entropy is a structural parameter that describes how the particles are arranged and can analyze the soil particle arrangement after F-T cycles. As F-T cycles increase, the probability entropy of the four samples gradually decreases (see Fig. 16). According to the definition of probability entropy, under freezing and thawing, the particle arrangement develops from a chaotic state to an orderly condition, and the directionality of the particle arrangement is getting better and better. This is because pore water undergoes phase change during the F-T cycle resulting in a certain volume of ice crystal structure. When an ice crystal wedges the adjacent soil particles, the particles are squeezed each other and undergo relative displacement. During the freezing process at low temperature, due to the freezing front, the moisture inside the soil tends to migrate towards the freezing front, which provides conditions for the displacement of soil particles. In addition, it can be found that the probability entropy of the $8 \%$ PCM modified soil is smaller than that of the other three samples. The arrangement of soil particles in the $8 \%$ PCM modified soil becomes more orderly after undergoing the freeze-thaw cycle, and the degradation effect of freeze-thaw resistance is more pronounced. 


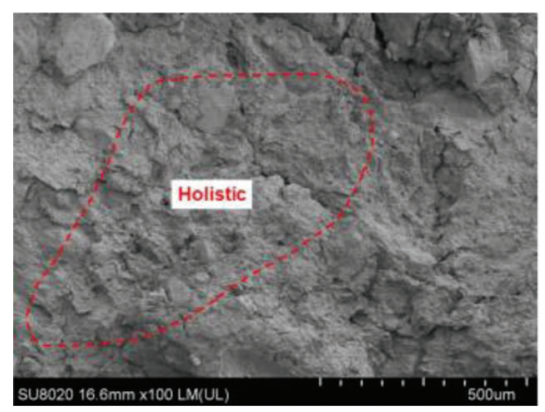

(a)

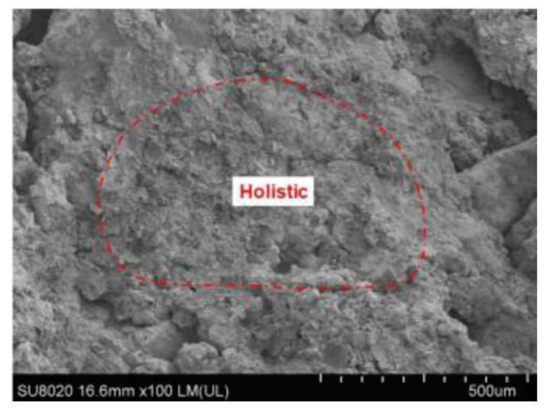

(d)

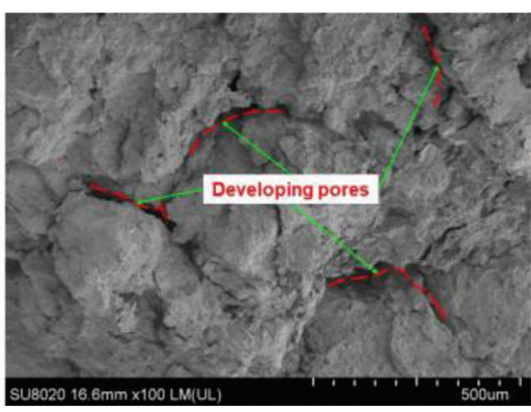

(b)

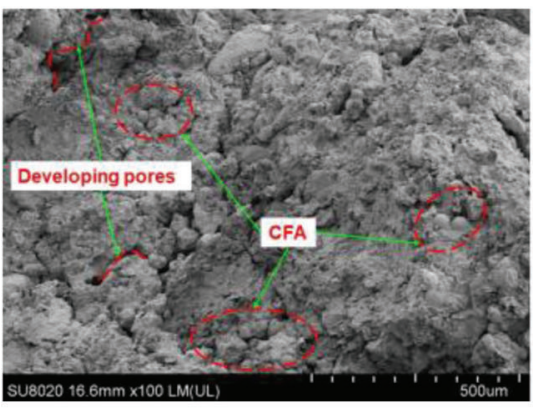

(e)

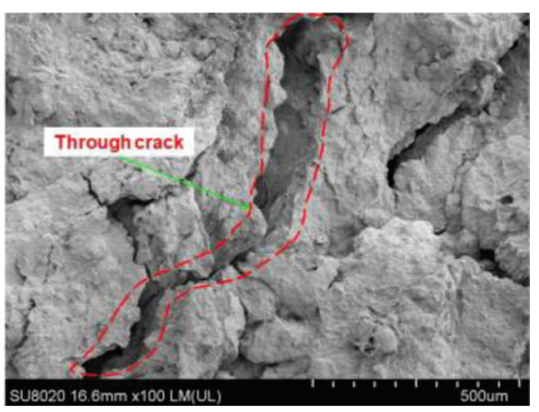

(c)

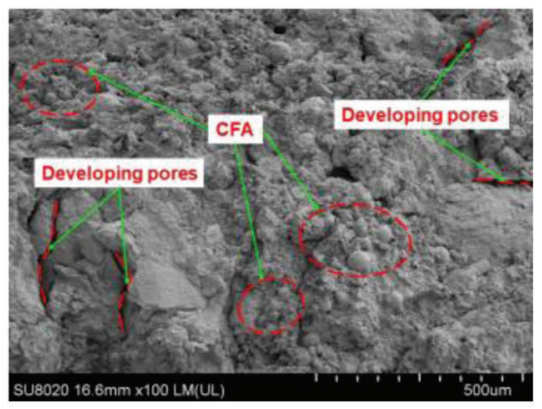

(f)

Figure 14: SEM photos of pure soil and CFA-8\% PCM samples at 100x (a) I-0, FT = 0 (b) I-0, FT = 1 (c) I$0, \mathrm{FT}=7$ (d) IC-P8, FT = 0 (e) IC-P8, FT = 1 (f) IC-P8, FT = 7

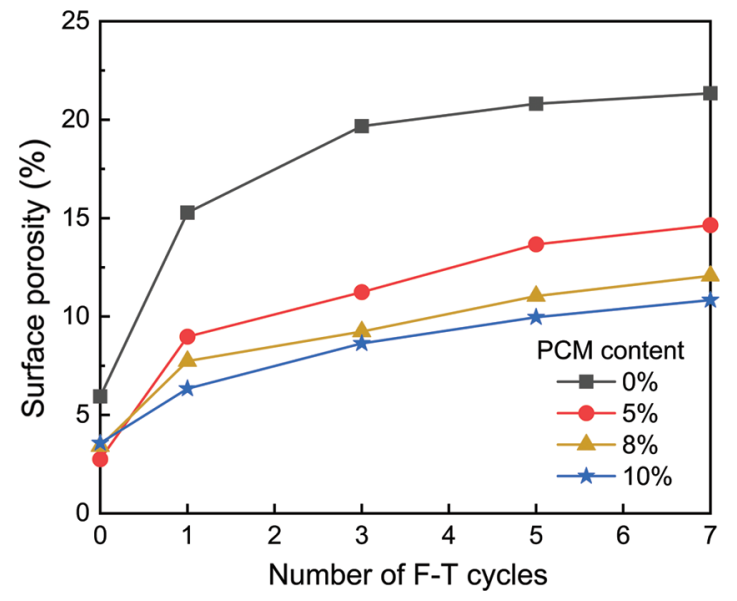

Figure 15: The porosity of the CFA-PCM sample surface porosity with the number of F-T cycles

\subsubsection{Analysis of PCM Improvement Mechanism}

Based on the above test results and analyses, the evolution process by which CFA-PCM improve the structural damage to expansive soil during F-T cycles is summarized in Fig. 17. When the soil is frozen (see Fig. 17b), on the one hand, CFA reduces the porosity of the soil and forms a three-dimensional mesh structure with soil particles, which adsorbs a certain amount of PCM and inhibits it from leaking. On the other hand, the heat released and stored by the PCM phase change counteracts external temperature changes, delaying the formation of ice lenses. This hinders the freeze of free water and weakens the 
forces of frost heaves with solid water. Therefore, the water-induced loss of clay minerals in the soil particles is reduced, the shrinkage of the soil particles is reduced, and the pores between the soil particles decrease in size. After the soil body melts (see Fig. 17c), the soil particles lose less water during the freeze. The clay minerals in the soil particles reduce water absorption, the expansion rate of the soil particles also decreases, which further weakens the soil pores. Therefore, the PCM stores heat as latent heat and can reduce positive and negative temperature fluctuations induced by the ambient environment. As a result, soil particles expand and contract less, and the repeated freezing and thawing of pore water can be reduced. To a large extent, fatigue damage to the soil microstructure (pore coarsening, loose structure, etc.) is alleviated.

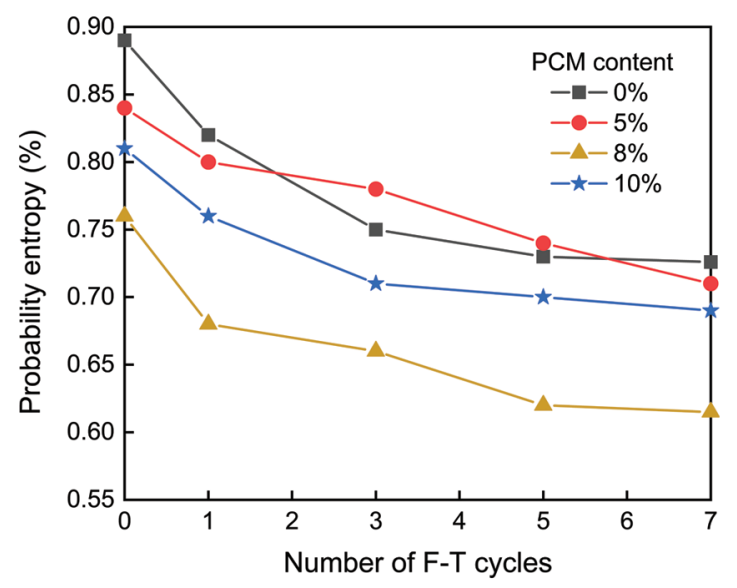

Figure 16: The porosity of the CFA-PCM sample porosity entropy with the number of F-T cycles

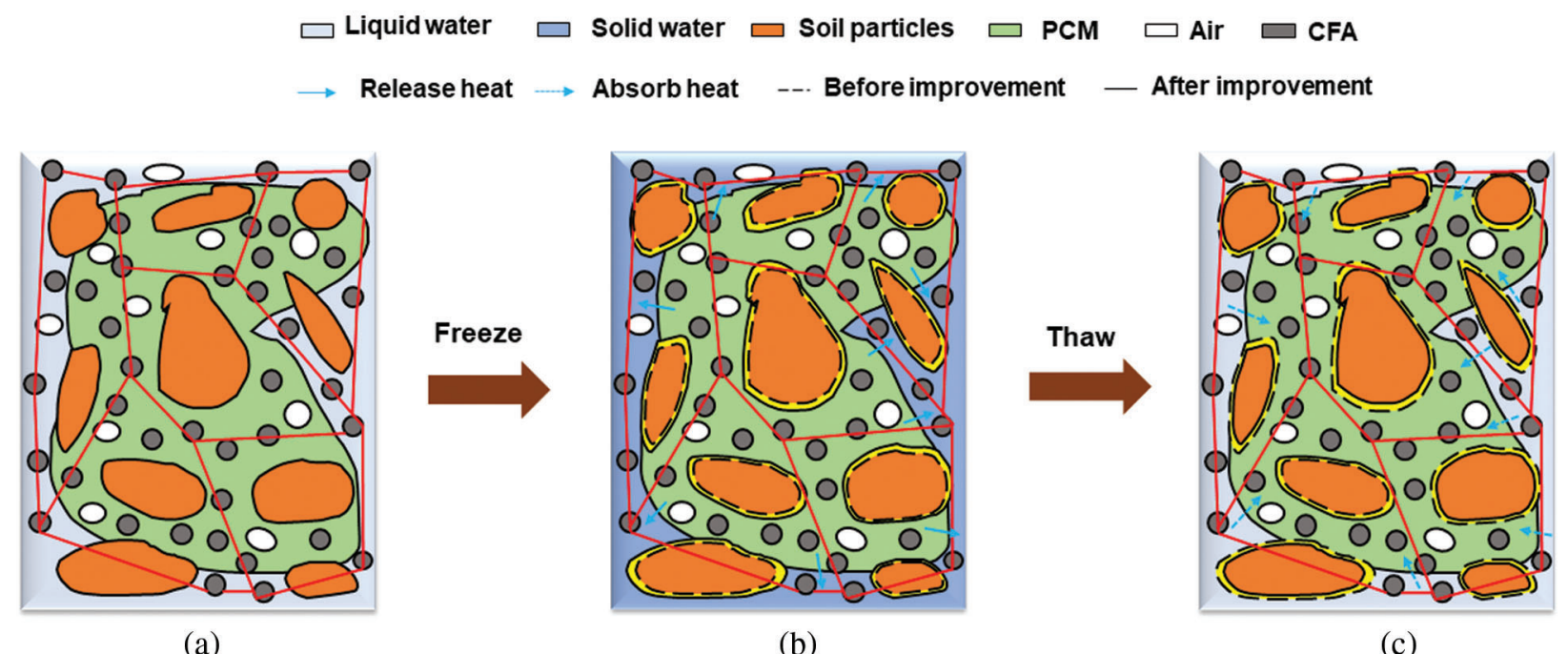

Figure 17: Schematic diagram of CFA-PCM used to treat thermal and mechanical properties of expansive soil in cold regions. (a) initial state (b) freezing frame (c) thawing frame 


\subsection{Prospect}

Earthworks in cold regions are often huge. From an economic point of view, it is impossible to add CFA-PCM to the entire frozen soil layer. So, once the optimal amount of incorporation is determined from laboratory tests, the optimal depth of incorporation needs to be determined. It is carried out through large-scale physical model tests or field tests, our follow-up work. Fig. 18 is the schematic diagram of the CFA-PCM treatment mechanism of the foundation soil of the canal in the cold region. When the outside temperature drops to $5^{\circ} \mathrm{C}$, the PCM undergoes a phase change to generate heat and release energy. In this way, the temperature gradient of the whole soil layer of the canal becomes gentle, and the internal temperature of the entire foundation soil rises. The optimal mixing depth is reached to meet the actual engineering construction needs.

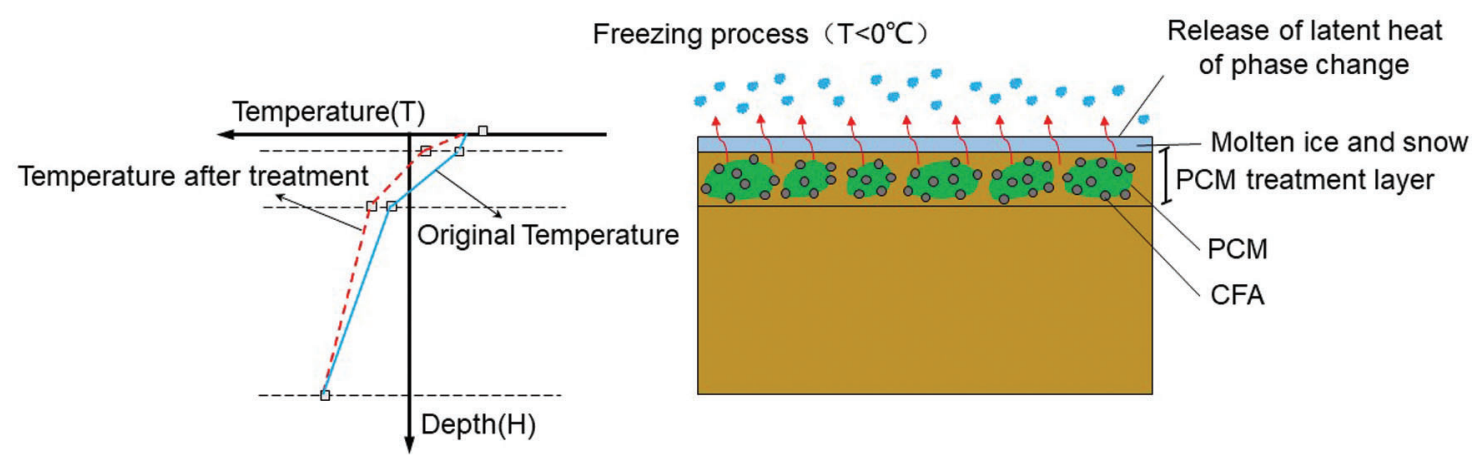

Figure 18: Schematic diagram of the CFA-PCM treatment mechanism of the foundation soil of the expansive soil canal in the cold region

\section{Conclusions}

This study investigated the effects of fly ash/paraffin composite phase change material on improving the characteristics of expansive soil samples subjected to F-T cycles. Here are the main findings of this experimental study:

1) CFA has strong adsorption of phase change paraffin, which reduces PCM leakage in the soil by more than $84 \%$ and improves PCM stability.

2) The heat released and stored by the CFA-PCM phase change resists the external temperature, delays the formation of ice lenses, and reduces the phase change latent heat in the soil. The phase change latent heat of the expanded soil is decreased by about 10.93\% when PCM (10\% content) is used. Consequently, the freezing time of the soil increases, the supercooling phenomenon also slowed down, and the thermal stability is improved.

3) During the F-T cycle, CFA-PCM significantly reduced the volume change of the soil, but with the increase of the content, the improvement effect gradually slowed down. CFA- $8 \%$ PCM is the optimal content so that the absolute value of the soil volume change rate is maintained at about $1 \%$.

4) PCM can improve the toughness of the soil to a certain extent, while CFA aggravates the brittleness of the soil. CFA-8\% PCM shows good superiority in restraining the strength attenuation of expansive soil.

5) After seven cycles, the surface porosity of the samples with the 4 PCM contents $(0 \%, 5 \%, 8 \%$ and $10 \%$ ) increased by $15.4 \%, 11.89 \%, 8.65 \%$ and $7.27 \%$, respectively. The microstructure shows that CFA-PCM reduces the porosity increase rate of expansive soil, thereby inhibiting the volume changes and attenuating the strength of expansive soil. 
6) The PCM in the soil cannot release and absorb $100 \%$ of the energy during the phase change. In addition, in actual earthwork, the PCM with the suitable phase change latent heat should be selected according to the actual climatic conditions and the target temperature of the project.

Acknowledgement: The authors sincerely thank the State Key Laboratory of Frozen Soil Engineering of China for providing the experiment conditions.

Funding Statement: This research was funded by the National Natural Science Foundation of China (51879166) and the Open Fund of the State Key Laboratory of Frozen Soil Engineering of China (SKLFSE201909).

Conflicts of Interest: The authors declare that they have no conflicts of interest to report regarding the present study.

\section{References}

1. Lu, Y., Liu, S., Alonso, E., Wang, L., Xu, L. et al. (2019). Volume changes and mechanical degradation of a compacted expansive soil under freeze-thaw cycles. Cold Regions Science and Technology, 157, 206-214. DOI 10.1016/j.coldregions.2018.10.008.

2. Shi, B., Jiang, H., Liu, Z., Fang, H. Y. (2002). Engineering geological characteristics of expansive soils in China. Engineering Geology, 67(1-2), 63-71. DOI 10.1016/S0013-7952(02)00145-X.

3. Chaduvula, U., Viswanadham, B. V. S., Kodikara, J. (2017). A study on desiccation cracking behavior of polyester fiber-reinforced expansive clay. Applied Clay Science, 142, 163-172. DOI 10.1016/j.clay.2017.02.008.

4. Ferber, V., Auriol, J. C., Cui, Y. J., Magnan, J. P. (2009). On the swelling potential of compacted high plasticity clays. Engineering Geology, 104(3-4), 200-210. DOI 10.1016/j.enggeo.2008.10.008.

5. Viswanadham, B. V. S., Phanikumar, B. R., Mukherjee, R. V. (2009). Effect of polypropylene tape fibre reinforcement on swelling behaviour of an expansive soil. Geosynthetics International, 16(5), 393-401. DOI 10.1680/gein.2009.16.5.393.

6. Murty, V. R., Krishna, P. H. (2006). Stabilisation of expansive clay bed using calcium chloride solution. Proceedings of the Institution of Civil Engineers-Ground Improvement, 10(1), 39-46. DOI 10.1680/ grim.2006.10.1.39.

7. Changizi, F., Ghasemzadeh, H., Ahmadi, S. (2021). Evaluation of strength properties of clay treated by nano- $\mathrm{SiO}_{2}$ subjected to freeze-thaw cycles. Road Materials and Pavement Design, 2, 1-18. DOI 10.1080/ 14680629.2021 .1883466 .

8. Okeke, C. A. U. (2020). Engineering behaviour of lime and waste ceramic dust-stabilized expansive soil under continuous leaching. Bulletin of Engineering Geology and the Environment, 79, 2169-2185. DOI 10.1007/ s10064-019-01648-2.

9. Chenarboni, H. A., Lajevardi, S. H., MolaAbasi, H., Zeighami, E. (2021). The effect of zeolite and cement stabilization on the mechanical behavior of expansive soils. Construction and Building Materials, 272, 1-10. DOI 10.1016/j.conbuildmat.2020.121630.

10. Du, J., Zhou, A., Lin, X., Bu, Y., Kodikara, J. (2020). Revealing expansion mechanism of cement-stabilized expansive soil with different interlayer cations through molecular dynamics simulations. Journal of Physical Chemistry C, 124, 14672-14684. DOI 10.1021/acs.jpcc.0c03376.

11. Mustapha, A. N., Zhang, Y., Zhang, Z., Ding, Y., Li, Y. (2021). Taguchi and ANOVA analysis for the optimization of the microencapsulation of a volatile phase change material. Journal of Materials Research and Technology, 3(11), 667-680. DOI 10.1016/j.jmrt.2021.01.025.

12. Marani, A., Madhkhan, M. (2021). Thermal performance of concrete sandwich panels incorporating phase change materials, An experimental study. Journal of Materials Research and Technology, 3(12), 760-775. DOI 10.1016/j. jmrt.2021.03.022. 
13. Si, W., Zhou, X. Y., Ma, B., Li, N., Ren, J. P. et al. (2015). The mechanism of different thermoregulation types of composite shape-stabilized phase change materials used in asphalt pavement. Construction and Building Materials, 98, 547-558. DOI 10.1016/j.conbuildmat.2015.08.038.

14. Vigneswaran, V. S., Kumaresan, G., Dinakar, B. V., Kamal, K. K., Velraj, R. (2019). Augmenting the productivity of solar still using multiple PCMs as heat energy storage. Journal of Energy Storage, 26, 101019. DOI 10.1016/j. est.2019.101019.

15. Choi, S. H., Park, J., Ko, H. S., Karng, S. W. (2020). Heat penetration reduction through PCM walls via bubble injections in buildings. Energy Conversion and Management, 221, 113187. DOI 10.1016/j. enconman.2020.113187.

16. Jiang, L., Zhang, H., Li, J., Xia, P. (2019). Thermal performance of a cylindrical battery module impregnated with PCM composite based on thermoelectric cooling. Energy, 188, 116048.1-116048.12. DOI 10.1016/j. energy.2019.116048.

17. Li, D., Zhang, C., Li, Q., Liu, C. Y., Arıc1, M. et al. (2019). Thermal performance evaluation of glass window combining silica aerogels and phase change materials for cold climate of China. Applied Thermal Engineering, 165, 114547. DOI 10.1016/j.applthermaleng.2019.114547.

18. Li, D., Wu, Y. Y., Wang, B. C., Liu, C. Y., Arıc1, M. et al. (2020). Optical and thermal performance of glazing units containing PCM in buildings: A review. Construction and Building Materials, 233, 117327. DOI 10.1016/j. conbuildmat.2019.117327.

19. Li, Q., Wang, Y. Q., Ma, L. Y., Arıc1, M., Li, D. et al. (2021). Effect of sunspace and PCM louver combination on the energy saving of rural residences: Case study in a severe cold region of China. Sustainable Energy Technologies and Assessments, 45, 101126. DOI 10.1016/j.seta.2021.101126.

20. Ryms, M., Lewandowski, W. M., Klugmann-Radziemska, E., Denda, H., Wcislo, P. (2015). The use of lightweight aggregate saturated with PCM as a temperature stabilizing material for road surfaces. Applied Thermal Engineering, 81, 313-324. DOI 10.1016/j.applthermaleng.2015.02.036.

21. Zhang, X., Xu, M., Liu, L., Chao, H., Zhao, Y. J. et al. (2019). Experimental study on thermal and mechanical properties of cemented paste backfill with phase change material. Journal of Materials Research and Technology, 9(2), 2164-2175. DOI 10.1016/j.jmrt.2019.12.047.

22. Manning, B. J., Bender, P. R., Cote, S. A., Lewis, R. A., Sakulich, A. R. et al. (2015). Assessing the feasibility of incorporating phase change material in hot mix asphalt. Sustainable Cities and Societies, 19, 11-16. DOI 10.1016/ j.scs.2015.06.005.

23. Lecompte, T., Bideau, P. L., Glouannec, P., Nortershauser, D., Masson, S. L. (2015). Mechanical and thermophysical behaviour of concretes and mortarscontaining phase change material. Energy and Buildings, 94, 5260. DOI 10.1016/j.enbuild.2015.02.044.

24. Farnam, Y., Krafcik, M., Liston, L., Washington, T., Erk, K. et al. (2016). Evaluating the use of phase change materials in concrete pavement to melt ice and snow. Journal of Materials in Civil Engineering, 28(4), 04015161. DOI 10.1061/(ASCE)MT.1943-5533.0001439.

25. Figueiredo, A., Lapa, J., Vicente, R., Cardoso, C. (2016). Mechanical and thermal characterization of concrete with incorporation of microencapsulated PCM for applications in thermally activated slabs. Construction and Building Materials, 112, 639-647. DOI 10.1016/j.conbuildmat.2016.02.225.

26. Mahedi, M., Cetin, B., Cetin, K. S. (2019). Freeze-thaw performance of phase change material (PCM) incorporated pavement subgrade soil. Construction and Building Materials, 202, 449-464. DOI 10.1016/j. conbuildmat.2018.12.210.

27. Liu, X., Tie, J., Wang, Z., Xia, Y., Wang, C. et al. (2021). Improved thermal conductivity and stability of $\mathrm{Na}_{2} \mathrm{SO}_{4} 10 \mathrm{H}_{2} \mathrm{O}$ PCMs system by incorporation of $\mathrm{Al} / \mathrm{C}$ hybrid nanoparticles. Journal of Materials Research and Technology, 12, 982-988. DOI 10.1016/j.jmrt.2021.02.096.

28. Liu, Z., Zou, R., Lin, Z., Gui, X., Chen, R. et al. (2013). Tailoring carbon nanotube density for modulating electroto-heat conversion in phase change composites. Nano Letters, 13(9), 28-35. DOI 10.1021/n1401097d. 
29. Chen, Z., Shan, F., Cao, L., Fang, G. (2012). Synthesis and thermal properties of shape-stabilized lauric acid/ activated carbon composites as phase change materials for thermal energy storage. Solar Energy Materials and Solar Cells, 102, 131-6. DOI 10.1016/j.solmat.2012.03.013.

30. Ji, H., Sellan, D. P., Pettes, M. T., Kong, X., Ji, J. et al. (2014). Enhanced thermal conductivity of phase change materials with ultrathin-graphite foams for thermal energy storage. Energy \& Environmental Science, 7(3), 118592. DOI 10.1039/C3EE42573H.

31. National standard of the People's Republic of China (2019). GB/T 50123-2019 Standard for Geotechnical Test Methods. Beijing: China Planning Press.

32. Wan, X. S., Lai, Y. M., Wang, C. (2015). Experimental study on the freezing temperatures of saline silty soils. Permafrost Periglacial Process, 26, 175-187. DOI 10.1002/ppp.1837.

33. Abdolghanizadeh, K., Hosseini, M., Saghafiyazdi, M. (2020). Effect of freezing temperature and number of freeze-thaw cycles on Mode I and Mode II fracture toughness of sandstone. Theoretical and Applied Fracture Mechanics, 105, 102428. DOI 10.1016/j.tafmec.2019.102428.

34. Hotineanu, A., Bouasker, M., Aldaood, A., Al-Mukhtar, M. (2015). Effect of F-T cycling on the mechanical properties of lime-stabilized expansive clays. Cold Regions Science and Technology, 119, 151-157. DOI 10.1016/j.coldregions.2015.08.008.

35. Pan, A., Wang, Y., Cao, Y., Zhang, H., Zhao, J. et al. (2020). Research on thermal properties of phase change thermal control materials $\mathrm{Bi}-21 \mathrm{In}-18 \mathrm{~Pb}-12 \mathrm{Sn}$ and $\mathrm{Ga}-13.5 \mathrm{Sn}$ with low melting point. Journal of Materials Research and Technology, 9(3), 3897-3906. DOI 10.1016/j.jmrt.2020.02.016.

36. Al-Yaqoub, T. H., Parol, J., Znidarcic, D. (2017). Experimental investigation of volume changes behavior of expansive soil. Applied Clay Science, 137, 22-29. DOI 10.1016/j.clay.2016.11.018.

37. Giro-Paloma, J., Oncins, G., Barreneche, C., Martinez, M., Ines Fernandez, A. et al. (2013). Physico-chemical and mechanical properties of microencapsulated phase change material. Applied Energy, 109, 441-448. DOI 10.1016/j. apenergy.2012.11.007.

38. Li, C., Fu, L., Ouyang, J. (2015). Kaolinite stabilized paraffin composite phase change materials for thermal energy storage. Applied Clay Science, 115, 212-220. DOI 10.1016/j.clay.2015.07.033.

39. Zhang, D., Li, K. (2007). Testing methods of thermal property of phase change materials. Materials Reports, 21(12), 103-105, 114. DOI 10.2514/1.26230.

40. Falayi, T., Okonta, F. N., Ntuli, F. (2016). The geotechnical and microstructural properties of desilicated fly ash lime stabilised expansive soil. Materials and Structure, 49(11), 4881-4891. DOI 10.1617/s11527-016-0831-7.

41. Gao, F., Kaiser, P. K., Stead, D., Eberhardt, E., Elmo, D. (2016). Strainburst phenomena and numerical simulation of self-initiated brittle rock failure. International Journal of Rock Mechanics and Mining Sciences, 116, 52-63. DOI 10.1016/j.jjrmms.2019.03.021.

42. Araki, H., Koseki, J., Sato, T. (2016). Tensile strength of compacted rammed earth materials. Soils Found, 56, 189204. DOI 10.1016/j.sandf.2016.02.003.

43. Lu, Y., Liu, S., Zhang, Y., Li, Z., Xu, L. (2019). Freeze-thaw performance of a cement-treated expansive soil. Cold Regions Science and Technology, 170, 102926. DOI 10.1016/j.coldregions.2019.102926.

44. Gu, K., Tang, C., Shi, B., Hong, J., Jin, F. (2014). A study of the effect of temperature on the structural strength of a clayey soil using a micropenetrometer. Bulletin of Engineering Geology and the Environment, 73, 747-758. DOI 10.1007/s10064-013-0543-y. 